\title{
They Buried Him in California
}

\author{
Catherine G. Tran ${ }^{1}$
}

Published online: 16 September 2016

(C) Springer Science+Business Media New York 2016

My father never walked, never strolled.

He only loomed, appearing so forcefully the air cracked like ice in hot water.

Whenever we heard the backdoor open,

a splinter of electricity scratched my back.

Crack! - my sisters and I scattered like struck marbles.

My mother fills bottles shaped like vases with bloody, purulent fluid.

She harvests it from a hole in my father's chest.

Her lips are firmly set like boulders, but her fingers are earthquakes, belying the ostensible calm of her tectonic plates.

Doctors come in to check on the mannequin in my father's bed.

(Are they doctors? Why are there so many of them?)

They descend like a flock of birds,

cooing quietly and readjusting their white feathers.

I understand their words as well as I understand birdsong,

but I catch the words "I'm so sorry"

More colorful birds flit in and out, but their efforts are in vain.

We fly to California later that week.

Years later, I am trailing a group of birds,

a heavy white coat pulling on my neck,

a birdsong on my lips.

I readjust my white feathers

as the doctor says "I'm so sorry"

Catherine G. Tran

Catherine.tran@unmc.edu

1 University of Nebraska College of Medicine, Omaha, Nebraska, USA 